\title{
Corpo e Gênero a partir do perspectivismo e multinaturalismo ameríndio
}

Marcele Morais ${ }^{1}$ Universidade Federal de Pernambuco

Resumo: Este artigo tem como foco uma discussão sobre gênero e corpo a partir do ponto de vista do perspectivismo e multinaturalismo ameríndio, tendo em vista sua capacidade de conceber a existência de múltiplas naturezas a partir da multiplicidade de corpos, todos atravessados pela condição de humanidade. Há uma enorme produção acerca do conceito de gênero, estando seu significado em constante disputa. Aqui, particularmente me concentro em um aspecto específico desse conceito: a separação colonial e ocidental entre natureza e cultura.

Palavras-chave: natureza; cultura; gênero; corpo; multinaturalismo; perspectivismo. 


\title{
Body and gender from the amerindian perspectivism and multinaturalism
}

\begin{abstract}
This article focuses on a discussion about gender and body from the amerindian perspectivism and multinaturalism point of view, given its capacity to conceive the existence of multiple natures from the multiplicity of the bodys, all crossed by a condition of humanity. There is a great production concerning the concept of gender which meaning is in a constant dispute. Here, particularly, I focus on a specific aspect of this concept: the western and colonial separation between nature and culture.
\end{abstract}

Keywords: nature; gender; body; multinaturalism; perspectivism.

\section{Cuerpo y género a partir del perspectivismo y multinaturalismo amerindio}

Resumen: Este artículo enfoca una discusión acerca de género y cuerpo a partir del perspectivismo y multinaturalismo amerindio, teniendo en cuenta su capacidad para concebir la existencia de múltiples naturalezas a partir de la multiplicidad de cuerpos, todos atravesados por la condición de humanidad. Hay una enorme producción acerca del concepto de género y su sentido está en disputa constante. Acá, en particular, me centro en un aspecto particular de ese concepto: la separación colonial y occidental entre la naturaleza y la cultura.

Palabras clave: naturaleza; género; cuerpo; multinaturalismo; perspectivismo. 
A colonialidade refere-se a uma matriz colonial de poder que exerce controle sobre a política, a economia, a sexualidade e a subjetividade, de modo a apagar as categorias das cosmologias latino-americanas que possuem suas lógicas próprias (MIGNOLO, 2010). Nessa linha de pensamento, tomarei como ponto de partida a perspectiva decolonial de Walter Mignolo (2010), pois a julgo adequada tanto porque o conjunto de problemas abordados no presente artigo situa-se na América Latina, o que exige considerar seus processos sociohistóricos específicos, quanto pela sua própria concepção de modernidade, que o autor argentino concebe como uma faca de dois gumes: não é possível falar de modernidade sem falar de colonialidade, uma não existe sem a outra. De outro modo, esse encontro colonial foi ontoformativo, o que significa dizer que ele criou uma nova realidade social a partir da instalação de uma estrutura colonizadora (CONNELL, 2012).

Diferentemente das cosmologias das sociedades ameríndias, que serão expostas ao longo do artigo, a modernidade organiza o mundo em categorias atômicas, homogêneas e separáveis: natureza/cultura, objetividade/subjetividade, mente/corpo, emoção/razão. Como aponta María Lugones (2019), essas dicotomias, que constituem uma lógica categorizante, foram impostas entre as populações da América Latina através de um projeto de transformação civilizatória que, acompanhado da colonização da memória, teve efeitos na compreensão que as pessoas têm de si mesmas.

Para pensar as relações entre corpo e gênero, foco particularmente na dicotomia natureza/cultura, uma das características centrais da modernidade. De modo geral, é possível afirmar que a epistemologia ocidental percebe a natureza como uma ameaça que precisa ser controlada, a fim de que não absorva a cultura (HARDING, 2019). Essa relação foi bastante utilizada como pressuposto básico para designar a divisão sexual entre homens e mulheres: a mulher é situada no domínio da natureza, enquanto o homem está no domínio da cultura. Se olharmos para um dos clássicos da sociologia, Durkheim, por exemplo, podemos perceber como a exclusão da mulher da esfera pública é um aspecto essencial para a harmonia e o funcionamento da sociedade (MARSHALL e WITZ, 2004). Sendo teorizada desse modo, pressupõe-se que as capacidades sociais e cognitivas das mulheres não foram plenamente desenvolvidas, o que implica uma natureza não-social. Felizmente, pensadoras feministas contestaram essa relação entre a mulher e a natureza, demonstrando como características que, à primeira vista, podem parecer naturais, são, na verdade, construções sociais (SCOTT, 2019).

Nesse contexto, situa-se o conceito de gênero que, na sua compreensão mais comum, reconhece as diferenças sociais entre homens e mulheres como consequências da diferença biológica (CONNELL, 2015). "Ser mulher" e "ser homem", a partir de uma determinada interpretação, são experiências fixadas pela natureza. Como pretendo deixar evidente ao longo do meu argumento, a impo- 
sição de tais dicotomias às sociedades ameríndias configura-se como mais um dos mecanismos da colonialidade e da colonialidade de gênero, que atravessa todo o processo de subjetificação do colonizado no sentido da "adoção/internalização da dicotomia homens/mulheres como construção social normativa uma marca civilizatória, de cidadania, de integração na sociedade civil" (LUGONES, 2019: 365). Aqui, a distinção entre moderno e não moderno torna-se produtiva na medida em que concebe o não-moderno não como pré-moderno, mas reconhece os mecanismos da modernidade para reduzir práticas, conhecimentos, relações e valores não-modernos a formas pré-modernas, assim, construindo-os em tensão com uma lógica dicotômica e hierarquizante (APARICIO e BLASER apud LUGONES, 2019). Essa distinção deixa evidente a tentativa de controlar, através da colonialidade, a existência de mundos com princípios ontológicos diferentes, roubando sua validade e contemporaneidade (LUGONES, 2019).

No entanto, Eduardo Viveiros de Castro (2004) chama atenção para a resistência do perspectivismo ameríndio aos termos dos debates epistemológicos ocidentais que põem sob suspeita a transponibilidade de suas "partições ontológicas". A dicotomia natureza/cultura não possui sentido no perspectivismo ameríndio porque ela não assume forma imóvel, fixa, pelo contrário: a relação entre natureza e cultura trata de configurações relacionais, de perspectivas móveis, de pontos de vista (VIVEIROS DE CASTRO, 2004: 231). Levando em consideração que conhecer, no perspectivismo ameríndio, é personificar, é "tomar o ponto de vista do que deve ser conhecido", uma outra dicotomia que também é central na organização do mundo ocidental, isto é, objetividade/subjetividade, não faz sentido nesse contexto. Isso ocorre porque o ponto de vista está no corpo, portanto, a diferença entre diferentes pontos de vista é dada a partir da especificidade da natureza que diferem os corpos (VIVEIROS DE CASTRO, 2004).

Dito isso, creio que as ferramentas que o perspectivismo ameríndio fornecem sejam um produtivo ponto de partida para pensar gênero e corpo, sobretudo quando levamos em consideração a relação que se estabelece entre natureza e cultura. Isto é, sabendo que a dicotomia entre natureza e cultura na epistemologia ocidental se traduz na dicotomia entre sexo e gênero, e a primeira não é capaz de dar inteligibilidade a um conjunto de experiências que se localizam em sociedades ameríndias, tomo como pressuposto que a última também não é adequada para tratar dessas mesmas realidades.

Embora o perspectivismo não tenha sido desenvolvido, a princípio, para tratar de relações de gênero, o dossiê "Corpo, terra, perspectiva: o gênero e suas transformações na etnologia" da "Amazônica: Revista de Antropologia" apresenta pesquisas que contribuem para afastar a ideia de que o perspectivismo seria reduzido apenas a uma interação entre humanos e não-humanos, sendo ausente as relações generificadas, o que significa reconhecer que as relações entre humanos e não-humanos são atravessadas por relações de gênero (BELAUNDE, MATOS e SANTOS, 2019). Nesse sentido, tais pesquisas indagam sobre a possibilidade de tratar o gênero como perspectiva na medida em que ele se associa, também, com outras relações dentro das sociedades etnografadas (ibid, 2019).

Diante do exposto, irei apontar brevemente algumas das limitações do conceito de gênero na sua acepção ocidental. Em seguida, buscarei localizar a discussão sobre sociologia do corpo na América Latina, a qual não pode ser pensada de maneira desconexa com a emoção. Por fim, pretendo apresentar o perspectivismo ameríndio para, então, apresentar as articulações feitas entre pers- 
pectivismo e gênero, chamando atenção para suas potencialidades no que diz respeito ao entendimento sobre o corpo.

\section{As categorias de gênero no pensamento ocidental}

O conceito de gênero é desenvolvido para explicar as desigualdades e diferenças entre homens e mulheres baseadas numa distinção social acerca do sexo, compreendido a partir de fundamentos biológicos. Isso porque a divisão masculino e feminino como ferramenta mobilizada para explicitar as diferenças entre homens e mulheres se torna insuficiente para explicar essas diferenças e desigualdades sociais.

Apenas a partir da década de 1970 que, no pensamento feminista, o conceito de gênero passa a ocupar lugar central quando iniciam seus estudos como categoria social. Em um primeiro momento, o gênero indicava que as diferenças sociais entre homens e mulheres são consequências da diferença biológica. No entanto, a relação implicada nessa definição é questionável, primeiramente, porque é possível pensar sujeitos "gendrados" não apenas nas relações de sexo, mas também nas relações de classe e raça (CONNELL, 2015; DE LAURETIS, 2019). Essa redução do gênero a uma causa de origem biológica também se torna problemática quando consideramos que, dentre outros problemas, essa definição não permite conceber as diferenças entre os próprios homens e as diferenças entre mulheres. Além disso, ela também implica uma compreensão dicotômica da realidade quando ela não o é, inserindo a diferença sexual numa dicotomia rígida, pressupondo que padrões culturais expressam diferenças corporais (CONNELL, 2015).

Tais limites tornam evidente os problemas de pensar "o ser mulher" e o "ser homem" como experiências fixadas pela natureza, pois, quando observadas mais profundamente, percebe-se que as características mais distintivas de cada gênero não são tão fixas e bem delimitadas como se imagina que é quando pensamos na existência, por exemplo, de homens "afeminados" ou de mulheres "masculinas" (CONNELL, 2015). Esses fatos demonstram a impossibilidade de corporificar todas as normas de gênero, pois sempre há um elemento que escapa, que não está de acordo com o que se é esperado. Não há nada que garanta que o ser que se torna mulher seja "fêmea" e o ser que se torna homem seja "macho" (BUTLER, 2017), porque há um lugar intermediário em que se localizam as pessoas "trans" ou "queer" (CONNELL, 2015).

No entanto, de um ponto de vista decolonial, até mesmo o conceito de transexualidade pode ser colocado sob crítica se o considerarmos como parte de um projeto branco colonial (BOELLSTORFF, 2014). Isso porque o gênero é uma imposição colonial (LUGONES, 2019), se olharmos para sociedades ameríndias (MATOS, 2019; GUIMARÃES, 2019; BELAUNDE, 2019), perceberemos como suas categorias nativas fazem cair por terra as conceituações referidas anteriormente. Isto é, sendo construído a partir das considerações que a biologia tem a dizer sobre o sexo, gênero e mudança de sexo, o conceito de gênero não dá conta das sociedades ameríndias, porque "ser mulher" e "ser homem" são experiências que estão relacionadas com o mundo espiritual, com a terra, com a organização social, ecológica e cosmológica (LUGONES, 2019). A construção da compreensão do corpo nessas sociedades, portanto, envolve elementos distintos daqueles postos pela modernidade, tendo em vista que o corpo físico não é a totalidade do corpo (SEEGER, DAMATTA e VIVEIROS DE CASTRO, 1979). 
Muitos dados etnográficos mostram como os corpos e os processos corporais fazem parte de um regime de solidariedade (MCCALLUM, 2013). Aqui tomo como exemplo uma pesquisa feita com os Airo-pai em que a autora busca enfatizar as relações de gênero de maneira interligada com o perspectivismo ameríndio, pois, em seu argumento, "ser capturado pela perspectiva do outro nem sempre se refere a um dilema entre comer e ser comido" (BELAUNDE, 2019: 660). A organização social dos Airo-pai está relacionada à maneira pela qual os seres celestiais olham para os homens e para as mulheres - as mulheres são vistas como filhotes de papagaio, porque elas, assim como os papagaios, se aninham dentro das árvores, enquanto os homens são vistos como filhotes de japu, porque, assim como os japus, eles tecem ninhos para criar seus pequenos (BELAUNDE, 2019).

Mulheres e homens são filhotes de pássaros diferentes porque, do ponto de vista dos seres celestiais, eles reproduzem-se separadamente e possuem hábitos contrastantes. As pessoas que podem comunicar-se com esses seres celestiais são os xamãs, para tanto, eles precisam mudar de pele, o que implica mudança de percepção e de linguagem. Essa pele é o revestimento corporal do centro de pensamento, afeto e memória pessoal, isto é, o coração (BELAUNDE, 2019). Dito isso, acredito que esse exemplo ilustra bem como o gênero opera de maneira bastante diferente em sociedades ameríndias dado a especificidade do fato de que "ser mulher" e "ser homem" são experiências que passam pelo relacionamento entre os animais considerados não-humanos e por múltiplas perspectivas. Demonstrando, assim, as articulações existentes entre o perspectivismo e o gênero nessas sociedades.

\section{Sociologia do corpo/emoções na América Latina}

Diante do exposto, acredito ser produtivo aproximar o pensamento de María Lugones (2019) e o de Adrián Scribano (2013) para pensar corpo e gênero, pois o adestramento dos corpos tal como citado por Scribano (2013) é útil para pensar o projeto colonial que, sob a justificativa de trazer a civilização para os povos nativos, serviu de justificativa para ter acesso aos corpos das pessoas pela exploração e pela violência (LUGONES, 2019). Além disso, a fim de enfatizar as limitações das categorias ocidentais de gênero como meios de e para interpretação das organizações sociais e experiências que não se localizam na Europa, trago também a discussão feita por Oyèrónke Oyěwùmí (2004) cujas reflexões destacam a importância de pensar as dinâmicas de determinados grupos a partir do seus próprios termos.

Primeiramente, faz-se importante discorrer sobre a maneira pela qual Scribano (2013) compreende o corpo. Segundo o autor, não é possível desenvolver uma sociologia do corpo sem uma sociologia das emoções e, para justificar sua afirmação, o autor utiliza três argumentos. O primeiro parte do fato de que as emoções são estados corporais, isto é, o corpo implica em um conjunto de processos perceptivos dos quais depende. Nesse contexto, os estudos das neurociências lhe servem como base uma vez que demonstram a impossibilidade da separação entre corpo e emoção, pois deixam evidente que a construção do corpo é feita a partir de uma interação entre capacidades e potencialidades biológicas e meio ambiente: o mundo nos constrói biologicamente ao mesmo tempo que nosso corpo é transformado fisicamente quando interagimos socialmente. Isso porque para que esse corpo se sustente, é necessário que sejam atendidas demandas biológicas. Contudo, esse processo não ocorre de maneira igualitária. 
Aqui tomo o exemplo dado pelo autor, o fato de que a distribuição e apropriação desigual de nutrientes regula o sistema neurofisiológico que sustenta diferentes estados de vida.

O segundo argumento de Scribano (2013) parte de um ponto de vista epistemológico, teórico e metodológico que entende a separação entre corpo e emoção como uma "ilusão representacionista" que cria objetos e métodos especializados, desconectados e distintos. De maneira geral, o que se torna mais fundamental aqui é a impossibilidade de tratar do corpo sem se referir às emoções, seja conceitualmente ou epistemologicamente. É preciso dar conta dessa conexão e relacionalidade porque não é adequado separar corpos e emoções em "compartimentos" diferentes. Em um sentido metodológico, a separação entre corpos e emoções coloca alguns problemas no que diz respeito à observação, registro e análise porque quando olhamos para os corpos também olhamos para as emoções e vice-versa.

Por fim, o autor chama atenção para o caráter construído dos corpos e das emoções e como eles operam na construção da subjetividade/individualidade. A atenção está voltada para como as emoções modelam o corpo no sentido de que elas podem conduzi-lo a determinados estados. A partir desses elementos, é possível pensar formas de exploração capitalista e colonialista que, por um lado, degrada os eixos naturais de reprodução biológica como a água, a terra e formas de energia, ao mesmo tempo que explora o ser social. De uma perspectiva materialista e fenomenológica, Scribano (2013) parte do pressuposto que é através dos nossos corpos que conhecemos o mundo, contudo, nossos corpos são adestrados por mecanismos de dominação capitalista e colonial que exploram a energia corporal. Esses mesmos mecanismos de dominação ainda são responsáveis pela regulação de sensações através das quais o mundo é apreendido e é nesse processo que a subjetividade é construída e que, por sua vez, molda o estado que esse corpo age no mundo.

No que diz respeito ao projeto colonial, a estratégia de adestramento dos corpos se torna importante porque demonstra como os homens e mulheres das sociedades indígenas não eram vistos como pessoas, mas como animais, bestas, sendo assim, a transformação que ocorreu com essas pessoas não é de caráter identitário, mas é uma transformação natural, e tal adestramento vem em conjunto com uma regulação de sensações (LUGONES, 2019; SCRIBANO, 2013). O cristianismo, nesse contexto, elemento que constitui esse projeto colonial, produziu mudanças drásticas na medida em que impôs a sua ideia de divisão entre bem e mal, de pecado e confissão cristã que serviram para marcar a sexualidade feminina como má (LUGONES, 2019). Essas ideias produziram novas formas do corpo se relacionar com o mundo dado que determinadas práticas corporais se tornam condenáveis, o adestramento, portanto, passa a ser necessário para se inserir na sociedade.

Além disso, Lugones (2019) ainda enfatiza o apagamento dos laços comunitários, do conhecimento sobre a agricultura, a natureza, a produção de utensílios que ocorre a partir da introdução de uma noção instrumental de natureza, ideia fundamental para o funcionamento do capitalismo, o que se aproxima da degradação dos meios de reprodução da vida biológica, nos termos de Scribano (2013). Isto é, as formas de dominação capitalista e colonial implicam em um olhar instrumental para a natureza, o que afeta diretamente a experiência corporal dos agentes sociais, posto que esses dependem da natureza para se manterem vivos (LUGONES, 2019; SCRIBANO, 2013). A água, por exemplo, precisa estar em condições utilizáveis para que as pessoas possam usufruir desse bem. 
No entanto, sua distribuição desigual traz problemas para aqueles que possuem dificuldade de acesso. Indo mais além, se considerarmos o exemplo dado anteriormente pelos Airo-pai (BELAUNDE, 2019), a noção instrumental de natureza produziria múltiplas consequências para estruturação dessa sociedade, sabendo que sua organização social e suas relações de gênero dependem fundamentalmente da natureza e das relações com os não-humanos.

À medida que a colonialidade se infiltra em todos os aspectos da vida por meio da circulação do poder no nível do corpo, do trabalho, da lei, na imposição de impostos e no aparecimento de desapropriações de propriedades de terras, sua lógica e eficácia são enfrentadas por pessoas diferentes cujos corpos, Eus relacionais, e relações com o mundo espiritual não seguem a lógica do capital. A lógica seguida por elas não é contraposta pela lógica do poder. Os movimentos desses corpos e dessas relações não se repetem; eles não se tornam estáticos e ossificados. (LUGONES, 2019: 372)

A colonialidade do gênero, um dos aspectos da colonialidade do poder (MIGNOLO, 2010), impôs uma lógica moderna categórica, hierarquizante e dicotomizada à organização social das sociedades indígenas (LUGONES, 2019). Como dito, as pessoas colonizadas eram vistas não como humanas, mas como animais que precisavam ser adestrados, o que explica porque elas não eram atribuídas de gênero: sendo animais, eram vistas como seres puramente sexuais, pecaminosos, do ponto de vista do cristianismo (LUGONES, 2019). Macho e fêmea são as categorias mobilizadas para classificar os colonizados, em contraposição com os termos homem e mulher, que assumem caráter normativo e caracterizam os colonizadores. Em uma ordem hierárquica que se organiza primeiramente a partir de um critério racial, os homens brancos e mulheres brancas estão acima dos negros e indígenas, e é seguida de um critério sexual (LUGONES, 2019).

Apesar de estar localizada em um contexto africano, que possui particularidades em comparação com os processos de colonização da América Latina, a socióloga Oyèrónkẹ Oyěwùmí (2004), na medida em que enfatiza as origens euro-americanas das categorias de gênero, reconhece, também, seus limites quando mobilizadas para interpretar experiências e epistemologias africanas. Nesse sentido, convém enfatizar que a crítica realizada pela autora focaliza na noção de família nuclear que, segundo seu argumento, é necessária para a inteligibilidade dos conceitos de "gênero" e "mulher" nas suas compreensões ocidentais. Para além de outros detalhes, tal aspecto justifica uma das razões pelas quais as categorias ocidentais de gênero não são capazes de dar conta de experiências africanas, mais especificamente, da organização social da sociedade Iorubá, sobre a qual a autora se debruça. Isso porque a família Iorubá não é generificada, o que implica reconhecer que não é através do gênero que as categorias de parentesco adquirem sentido, mas por meio da "idade relativa". Embora esteja se referindo à sociedade Iorubá, tal crítica também se adequa a determinados contextos ameríndios, como demonstrarei mais à frente (GUIMARÃES, 2019).

Construindo um projeto feminista decolonial que se opõe à lógica ocidental de produção de gênero, Lugones (2019) pensa a resistência à colonialidade dos gêneros a partir das diferenças coloniais. Essa resistência é a "tensão entre subjetivação e a subjetividade ativa, o senso mínimo de agência necessário para que a relação oprimir/resistir seja ativa, sem recorrer ao senso máximo de agência da subjetividade moderna" (LUGONES, 2019: 362). Como meio possível para 
um feminismo decolonial da resistência, a autora enfatiza como a infrapolítica2 possibilita que agentes sociais construam novos significados de resistência que abrem caminho para a libertação, porque o espaço público é negado para os colonizados. Sabendo que o encontro colonial provoca transformações no nível da subjetividade, as pessoas colonizadas ocupam um lócus fraturado tendo em vista que a colonização não ocorre no vazio, mas em um lugar onde habitam pessoas que já possuem sua cosmologia própria, e ele opera na tentativa de apagar a memória e os conhecimentos delas (LUGONES, 2019). Então, a tensão entre ser oprimido e resistir constitui a subjetividade ativa na medida em que o colonizado busca construir formas de relações alternativas dentro desse mundo alterado pela colonização, a partir do aprendizado com os outros e outras que também resistem à diferença colonial.

O corpo é o meio pelo qual conhecemos o mundo social, e como visto, faz-se importante enfatizar os processos colonialistas que alteraram profundamente as sociedades ameríndias e produziram efeitos nas subjetividades corporificadas (GUIMARÃES, 2019; LUGONES, 2019; SCRIBANO, 2013). Portanto, sabendo que os corpos dos colonizados não eram vistos nem como sendo corpos humanos (o que evidencia a diferença normativa que organiza as pessoas entre humanos e não-humanos), foi necessário um adestramento desses corpos para que as energias dessas pessoas estivessem de acordo com a lógica moderna e capitalista, que implica uma maneira particular de sentir e se relacionar com o mundo sobretudo em decorrência do apagamento de elementos que são essenciais para cosmologias ameríndias.

\section{Perspectivismo e multinaturalismo ameríndio}

No presente tópico irei ater-me a apresentar o perspectivismo e o multinaturalismo ameríndio posto que sua forma de compreender o corpo, concepção que atravessa toda a organização social, coloca em questão os pressupostos ocidentais devido à maneira pela qual as noções de natureza, cultura, humano e não-humano são dispostas em suas cosmologias. Para compreender o perspectivismo e multinaturalismo ameríndio, deve-se ter em mente que a noção de corporalidade, bem como a noção de pessoa, assumem lugar central em suas cosmologias (SEEGER, DAMATTA e VIVEIROS DE CASTRO, 1979; VIVEIROS DE CASTRO, 2004). Gostaria chamar atenção, primeiramente, para as dicotomias natureza/cultura e sujeito/objeto a fim de tornar evidente por qual motivo elas não dão conta de tratar a complexidade das cosmologias ameríndias.

No que diz respeito à dicotomia natureza/cultura, ela é estruturadora da epistemologia ocidental no sentido de que molda nosso olhar para a cultura: concebemos a existência da multiplicidade de culturas e supomos a unicidade da natureza. O perspectivismo e o multinaturalismo exigem que essas categorias sejam redistribuídas porque pressupõem a multiplicidade de naturezas e a uni-

\footnotetext{
${ }^{2}$ Um exemplo concreto pode ser ilustrado através da pesquisa realizada por Guimarães (2019) que chama atenção para atuação das mulheres Sanöma nos conflitos com pessoas não indígenas. O problema que orienta a pesquisa da autora diz respeito à soberania alimentar do referido grupo, porque, tendo em vista que doenças e altas taxas de desnutrição em crianças estavam acometendo esse grupo, instituições de saúde realizaram um relatório de seus hábitos para investigar suas causas. Contudo, na medida em que mobilizou conceitos que não dão inteligibilidade ao modo de vida dos Sanöma, tal relatório não levou em consideração suas particularidades, o que produz um conjunto de problemas porque seu modo de vida foi considerado o responsável pelas doenças e altas taxas de desnutrição. Nesse contexto, as mulheres e mães Sanöma, que são responsáveis pela alimentação das crianças, apontaram problemas nos relatórios: um deles diz respeito à desconsideração do tipo de família que caracteriza o grupo, em que o cuidado não é responsabilidade apenas da mãe. Além disso, ao se imporem diante de homens brancos, ocuparam, também, uma posição mais comumente ocupada pelos homens Sanöma. Isso porque, como ressalta a autora, os não-indígenas buscavam estabelecer um diálogo com os homens de tal grupo, assim como segue uma lógica ocidental de organização da esfera pública: enquanto os homens lidam com questões que dizem respeito ao coletivo, as mulheres estão voltadas para questões do lar.
} 
versalidade da cultura. $\mathrm{O}$ corpo desempenha papel fundamental porque nele está implicada uma natureza particular. Contudo, o que é natureza para uns, pode ser cultura para outros (VIVEIROS DE CASTRO, 2004), isso porque essas categorias "não assinalam regiões do ser", mas são "perspectivas móveis" (VIVEIROS DE CASTRO, 2002: 349). Nesse sentido, assume-se a perspectiva do outro quando assumimos o corpo do outro.

Tal ideia possui relação com a ideia de sujeito/objeto, dicotomia que orienta a epistemologia ocidental pois pressupõe que, para um sujeito conhecer um objeto, é necessário que ele aja de maneira impessoal para que suas próprias impressões não interfiram no processo de apreensão do objeto. De outro modo, conhecer é objetivar, é ser capaz de reconhecer o que é intrínseco do objeto (VIVEIROS DE CASTRO, 2004). O pensamento ameríndio desfaz tal dicotomia porque, para conhecer, é necessário personificar, é necessário assumir o ponto de vista daquele que deve ser conhecido (VIVEIROS DE CASTRO, 2004).

Sabendo desses pressupostos, é possível indicar como as relações que organizam as sociedades ameríndias são profundamente diferentes do que postula a epistemologia ocidental. Distanciando-se de uma divisão normativa entre humanos e não-humanos, o perspectivismo nos mostra uma outra maneira de relacionar-se com os seres humanos, os animais e "outras subjetividades que povoam o universo" (VIVEIROS DE CASTRO, 2002: 350). O referencial não é a espécie, mas a condição humana que perpassa todo o universo. No entanto, as coisas não são humanas o tempo inteiro umas com as outras: nos vemos como seres humanos e quando olhamos para os animais nós os vemos como nãohumanos, do mesmo modo, quando os animais se vêem eles se vêem como seres humanos e quando nos olham eles nos vêem como não-humanos (VIVEIROS DE CASTRO, 2002).

Como afirma Viveiros de Castro (2002), essa concepção se associa com a ideia de que a "roupa" de cada espécie é um envoltório, um corpo, que esconde uma forma interna humana, visível apenas aos olhos da própria espécie. Essa forma interna é o espírito animal, marcada por uma subjetividade semelhante à consciência humana, que é materializável no corpo e ocultado por essa "roupa" animal. Como dito anteriormente, para conhecer é necessário personificar, assumindo o ponto de vista daquele que deve ser conhecido, o que se justifica pelo fato de que são os pontos de vista que criam os sujeitos no perspectivismo ameríndio.

Nesse sentido, o ponto de vista está no corpo, as diferenças entre os pontos de vista é dada pela especificidade dos corpos, o que explica o porquê animais vêem coisas diversas da mesma forma que nós. O corpo, portanto, no pensamento ameríndio, é "como um feixe de afecções e capacidades", bem como é "o modo pelo qual a alteridade é apreendida como tal" (VIVEIROS DE CASTRO, 2004: 240), o que está relacionado com a forma que cada corpo é afetado. Em suma, o exemplo trazido por Viveiros de Castro (2004) ilustra bem: quando os índios se depararam com os europeus, não se tratava de descobrir se eles possuíam alma, questão que preocupava esses colonizadores, mas de descobrir se compartilhavam das mesmas afeç̧ões que os corpos daquelas almas.

\section{Articulações entre perspectivismo e gênero}

Levando em consideração a discussão anterior, Viveiros de Castro (2004) trata do perspectivismo a partir de uma relação entre presa e predador, contudo, como ressaltado no início do artigo, ser capturado pela perspectiva do outro 
nem sempre diz respeito à situação de comer ou ser comido, sendo possível pensá-lo também de maneira articulada com relações de gênero, assim como demonstrou Belaunde (2019) e Otero dos Santos (2019) em suas pesquisas etnográficas feitas a partir de contextos indígenas. Por outro lado, há também trabalhos que se apropriam das ferramentas analíticas e teóricas fornecidas pelo perspectivismo para pensar a transição de gênero em contextos diferentes dos quais ele foi construído, como fez Maluf (2001; 2002). Dito isso, julgo produtivo partir das articulações feitas entre perspectivismo ameríndio e gênero para pensar possíveis contribuições analíticas e políticas para as reflexões sobre esse último em um sentido mais amplo.

Apesar de existir uma imensa produção teórica feminista que indique as limitações do conceito de gênero como diferença sexual (CONNELL, 2015; DE LAURETIS, 2019; BUTLER, 2017; LUGONES, 2019; FAUSTO-STERLING, 2001), bem como dados antropológicos e etnográficos que demonstram como os significados de sexo e gênero podem variar em função do tempo e espaço (BELAUNDE, 2019; BELAUNDE, MATOS e SANTOS, 2019), corpos trans e nãobinários ainda são vistos e colocados em termos patologizantes. Como Eveline Rojas (2015) chama atenção, o corpo trans, no discurso médico e psiquiátrico, ainda é visto como uma patologia, ou a partir de termos que são baseados no sistema sexo/gênero heteronormativo.

Levando em consideração tal problema, volto o olhar para etnografias que tomam como central a produção de gênero e que fazem articulações entre gênero e o perspectivismo ameríndio. Primeiramente, ressalto alguns trabalhos que se propuseram a refletir sobre o processo de transição de gênero a partir do aporte fornecido pelo perspectivismo (VIVEIROS DE CASTRO, 2004; MALUF, 2002). Dito isso, a transição de gênero permite que uma pessoa assuma a perspectiva do não-humano a partir do seu deslocamento como sujeito que se dá através da mudança corporal. É nesse movimento em direção ao outro que se constrói uma subjetividade corporificada:

\footnotetext{
Aquele que estruturalmente se encontra na posição de sujeito busca se construir contingencialmente como sujeito, não mais na posição estruturalmente fixada, mas na experiência instável da transformação - do devir como movimento sem fixação final. Não são os peitos femininos de Agrado o que ela tem de mais autêntico, mas a experiência vivida da metamorfose, inscrita naqueles seios, a subjetividade corporificada que se constrói nesse movimento em direção ao outro. (MALUF, 2002: 151)
}

Maluf chama atenção para a instabilidade do processo de transformação do sujeito no processo de transição de gênero, o constante devir, posto que é a própria experiência vivida que permite esse movimento em direção ao outro. Não existe, portanto, um ponto final para esse sujeito. A "perspectiva móvel”, em um sentido heurístico, se torna evidente na medida em que esse mesmo sujeito, ao se deslocar de um lugar estruturalmente fixado, se constrói ao longo desse processo (MALUF, 2002). É possível articular tais reflexões com as feitas por Rosa (2019) na medida em que essa última destaca o processo de "virar mulher" que um indígena Ticuna passa.

Sua pesquisa aborda o modo como um jovem indígena habita normas de gênero e, consequentemente, de parentesco, pois essas possuem caráter relacional, tendo em vista a organização social estabelecida entre os Ticuna. A situação do jovem Nguyaecüe chama atenção porque, declarando sua falta de desejo de casar com uma prima cruzada, persiste na sua condição de solteiro, o que se torna motivo para julgamentos por parte de seus conterrâneos. Além disso, o jovem também é tratado como "caigüwaecu”, estatuto que se refere à sexualida- 
de e, mais especificamente, pode ser traduzido como "homem que usa ânus como vagina de mulher" (ROSA, 2019: 713).

Apesar disso, o jovem deseja se casar, contudo, com um outro homem e é nesse sentido que ele passa a habitar outras normas de gênero características do Ticuna, uma vez que, para realizar tal ação, precisa ocupar outra perspectiva de gênero, isto é, a posição de gênero feminina. Nesse contexto, a aquisição de gênero está relacionada "aos modos de saber produzir-se enquanto pessoa e parente através do exercício da incorporação das capacidades femininas ou masculinas" (ibid: 719). Embora tenha recebido comentários negativos de parentes e de figuras políticas importantes do local, Nguyaecüe persiste nesse processo, reconhecendo que desde criança não apenas realizava atividades que as mulheres Ticuna costumam fazer, como também gosta de fazê-las. Dois componentes são necessários nesse processo: a adoção e o casamento. Portanto, para viver enquanto mulher, Nguyaecue que passa a ser chamada de Nega, toma para si essas duas tarefas.

Ao fim, apesar de ter encontrado resistência por parte de seus conterrâneos, como já ressaltado, Nega consegue ser reconhecida como tal no local onde mora. Diante disso, percebe-se que o processo pelo qual Nega passa demonstra como a "subjetividade corporificada" é constituída nessa mudança de posição posto que, na medida em que o corpo é alterado (a jovem relata que pinta as unhas e usa roupas de mulheres, por exemplo), ela se torna capaz de construir sua subjetividade por meio de determinadas experiências, como a do casamento como um homem, por exemplo, que antes não era possível. Percebe-se, então, que dentro do contexto Ticuna "ser homem" e "ser mulher" não são experiências fixadas pela natureza se considerarmos as alterações de status que o corpo está sujeito. Isto é, quando o sujeito realiza o movimento de mudança e transformação tanto através da adoção de práticas performativas de gênero quanto de práticas que envolvam algum nível de modificação corporal.

Há outros contextos ameríndios nos quais a produção de gênero perpassa outras dinâmicas, como é o caso dos Matses, tal como etnografado por Matos (2019). Um dos elementos que constituem a história desse grupo indígena, é o ritual de iniciação masculina: espíritos visitam a aldeia para introduzir os homens mais jovens em uma nova fase de suas vidas, que os fornecessem amadurecimento e crescimento. O que chama atenção, nesse ritual, é a impossibilidade das mulheres matses olharem para os espíritos, o que evidencia uma assimetria de gênero entre tais grupos. Convém ressaltar, contudo, a ênfase que Matos (2019) atribui a não utilização de conceitos ocidentais, como o de "dominação masculina", para compreensão dessa relação, tendo em vista trabalhos que demonstraram a não pertinência desse em contextos ameríndios.

A autora sugere que o perigo que caracteriza a exposição do olhar das mulheres aos espíritos está relacionado à perspectiva e constituição desses corpos. Portanto, para compreender as razões pelas quais o ritual assume tal configuração, é necessário considerar o modo como os homens matses e mulheres matses produzem seus corpos e, consequentemente, seu gênero. É o corpo que estabiliza a multiplicidade da alma, sempre para o sujeito de referência (LIMA, 1996; TAYLOR e VIVEIROS DE CASTRO, 2006 apud MATOS, 2019), isto é, tornar-se corpo para alguém depende do olhar do outro. Posto isso e considerando o corpo como "feixe de afecções e capacidades", os homens matses podem ser vistos pelos espíritos porque adquirem as capacidades e afecções dos espíritos, o que não ocorre com as mulheres. A constituição dos corpos masculinos e femininos envolve a aplicação de "substâncias-potências" vegetais e animais e o aprendi- 
zado com parentes: enquanto as mulheres lidam com alimentos doces, por exemplo, os homens os evitam (MATOS, 2019). Atendo-se a esse fato, as diferenças entre homens e mulheres decorrem da aplicação distinta dessas substâncias.

Considerando as contribuições de Belaunde (2019) e Matos (2019), chamo atenção para as articulações entre perspectivismo e gênero e como em contextos ameríndios esse último conceito é atravessado por múltiplos fatores, não estando reduzido à construção social das diferenças biológicas. Aspecto que está em conformidade com o que Lugones (2019) destaca: a organização social das populações latino-americanas - no presente caso, as sociedades ameríndias - dependem da natureza e das relações com não-humanos, não existindo a comum separação entre natureza e cultura, característica comum à epistemologia ocidental. No sentido que aponta a autora apresenta, a infrapolítica apresenta-se aqui como um caminho possível para que tais corpos possam produzir formas de resistência à lógica moderna capitalista dominante.

Diante disso, um dos aspectos que julgo ser mais enriquecedor do perspectivismo e multinaturalismo ameríndio é o modo como as noções de natureza e cultura são mobilizadas, porque sua "redistribuição" permite que a diferença entre os corpos não seja vista como um problema a ser resolvido, nem seja motivo para nenhum tipo de rebaixamento social do outro tendo em vista que a humanidade é uma condição que perpassa todo o universo. Comparativamente, aquelas pessoas que se movimentam em direção a outros gêneros, assim como fez Nguyaecüe, mudando de corpo e, consequentemente, suas capacidades de ser afetado, provavelmente possuem algo a dizer e a ensinar levando em consideração sua experiência de passagem por outras posições que implicam outros modos de ser e de se relacionar no mundo.

Em suma, realizo este exercício de olhar para o perspectivismo e multinaturalismo ameríndio a fim de contribuir com as reflexões conceituais e políticas sobre gênero, e como proposta para tensionar bases epistemológicas e ontológicas para que possamos nos conectar com perspectivas outras, de modo a alterar e ampliar a forma que nos relacionamos com o mundo social.

\section{Conclusão}

Partindo de uma perspectiva decolonial, busquei demonstrar as dinâmicas de opressão específicas que atravessam as populações latino-americanas, bem como a colonialidade se apresentou como um projeto danoso em múltiplas esferas da vida, sendo a própria construção da concepção de corpo fruto dessas dinâmicas de violência que apagam os conhecimentos nativos e impõe sistemas de pensamento outros - dicotômicos e hierarquizantes (MIGNOLO, 2010; LUGONES, 2019; SCRIBANO, 2013). Nesse sentido, tais sistemas não dão conta de pensar a realidade das sociedades ameríndias porque a própria realidade se demonstra mais complexa que as dicotomias parecem ser. Como visto, as noções de "ser mulher" e "ser homem" como experiências fixadas pela natureza não fazem sentido se aplicadas às sociedades ameríndias, pois o modo que essas últimas dispõem suas noções deixa evidente a impossibilidade de "fixar" as perspectivas que, por sua vez, decorrem do corpo.

Como Belaunde (2019) percebeu, o perspectivismo ameríndio vai mais além de um dilema entre ser presa e predador, caracteriza toda uma cosmologia de modo que também perpassa as relações de gênero. Nesse sentido, a expansão do perspectivismo a partir das relações de gênero é produtiva para pensar modos 
de produção do corpo que não sejam atravessados apenas pelos elementos característicos das epistemologias ocidentais e, consequentemente, da lógica colonial. Isso porque os corpos das pessoas de determinadas sociedades ameríndias são construídos a partir de relações específicas com a natureza, a cultura, o humano e o não-humano. Por fim, creio que a lógica que constitui o perspectivismo permite olhar para os corpos de modo a evitar um possível rebaixamento social na medida em que considera relações de múltiplas naturezas na produção do gênero e do corpo, como também considera a condição de humano como característica de todos os seres.

Recebido em 31 de janeiro de 2021.

Aprovado em 22 de abril de 2021.

\section{Referências}

ALATAS, Syed Farid; SINHA, Vineeta. "Introduction". In: Sociological Theory Beyond the Canon. Londres: Palgrave/Macmillan, 2017. pp.1-15.

BELAUNDE, Luisa Elvira. O ninho do japu: perspectivismo, gênero e relações interespécies airo-pai. Amazônica - Revista de Antropologia, 11 (2): 657-687, 2019.

BELAUNDE, Luisa Elvira; MATOS, Beatriz de Almeida, OTERO DOS SANTOS, Julia. Corpo, terra, perspectiva: o gênero e suas transformações na etnologia. Amazônica - Revista de Antropologia, 11 (2): 391-412, 2019.

BOELLSTORFF, Tom; CABRAL, M; CARDENAS, M. Decolonizing transgender: A roundtable discussion. Transgender Studies Quarterly, 1 (3): 419-439, 2014.

BUTLER, Judith. Problemas de Gênero. $13^{\circ}$ ed. Rio de Janeiro: Civilização Brasileira, 2017.

CONNELL, Raewyn. Gênero: uma perspectiva global / Raewyn Connell, Rebecca Pearse; tradução e revisão técnica Marília Moschkovich. São Paulo: n.Versos, 2015 .

CONNELL, Raewyn. A iminente revolução na teoria social. Revista Brasileira de Ciências Sociais, 27 (80): 9-20, 2012. 
DE LAURETIS, Teresa. “Tecnologia de gênero”. In: HOLLANDA, Heloísa Buarque de (org.). Pensamento Feminista Brasileiro - conceitos fundamentais. Rio de Janeiro: Bazar do Tempo, 2019.

GUIMARÃES, Sílvia Maria Ferreira. "Agência das mulheres Sanöma e a ativação de cosmopolíticas”. Amazônica - Revista de Antropologia, 11 (2): 583-605, 2019.

FAUSTO-STERLING, Anne. Dualismo em duelo. Cadernos Pagu. 17/18: 9-79, 2001.

HARDING, Sandra. "A instabilidade das categorias analíticas na teoria feminista”. In: Pensamento Feminista Brasileiro - conceitos fundamentais / Audre Lorde... [et al.]; organização Heloísa Buarque de Hollanda. Rio de Janeiro: Bazar do Tempo, 2019.

KOURY, Mauro Guilherme Pinheiro; SCRIBANO, Adrián. Sociologia e Antropologia dos Corpos e das Emoções. RBSE - Revista Brasileira de Sociologia da Emoção, 11 (33): 645-653, 2012.

LUGONES, María. "Rumo a um feminismo decolonial”. In: HOLLANDA, Heloísa Buarque de (Org.). Pensamento Feminista Brasileiro - conceitos fundamentais. Rio de Janeiro: Bazar do Tempo, 2019.

MALUF, Sônia Weidner. Corporalidade e desejo: Tudo sobre minha mãe e o gênero na margem. Estudos Feministas, 10 (1): 143-153, 2002.

MALUF, Sônia Weidner. Corpo e corporalidade nas culturas contemporâneas: abordagens antropológicas. Esboços: histórias em contextos globais, 9 (9): 87101, 2001.

MCCALLUM, Cecília. Nota sobre as categorias "gênero" e "sexualidade" e os povos indígenas. Cadernos Pagu, 41: 53-61, 2013.

MIGNOLO, Walter. Desobediencia epistémica: retórica de la modernidad, lógica de la colonialidad y gramática de la descolonialidad. Buenos Aires: Ediciones del signo, 2010.

OTERO DOS SANTOS, Julia. Sobre mulheres brabas: ritual, gênero e perspectiva. Amazônica - Revista de Antropologia, 11 (2): 607-636, 2019.

OYĚWÙMÍ, Oyèrónké. Conceituando o gênero: os fundamentos eurocêntricos dos conceitos feministas e o desafio das epistemologias africanas. CODESRIA Gender Series, 1 (1): 1-10, 2004.

ROJAS, Eveline Gama. Trans narrativas do self: uma análise a partir de diários virtuais de transição transexual no Youtube. Tese de Doutorado, Sociologia, UFPE, 2015.

ROSA, Patrícia Carvalho. Sobre as diferentes formas de habitar as normas e ativar modulações no parentesco: um caso Ticuna. Amazônica - Revista de Antropologia, 11 (2): 711-738, 2019.

SCRIBANO, Adrián. Sociología de los cuerpos/emociones. Revista Latinoamericana de Estudios sobre Cuerpos, Emociones y Sociedad - RELACES. 4 (10): 93-113, 2012-2013.

SEEGER, Anthony; DAMATTA, Roberto; VIVEIROS DE CASTRO, Eduardo. A construção da pessoa nas sociedades indígenas brasileiras" Boletim do Museu Nacional, Série Antropologia, 32: 2-19, 1979. 
VIVEIROS DE CASTRO, Eduardo. Perspectivismo e multinaturalismo na América indígena. O que nos faz pensar, 18, setembro de 2004. (Texto principal) 